\title{
Low self-concept in poor readers: prevalence, heterogeneity, and risk
}

\author{
Genevieve McArthur ${ }^{\text {Corresp., }}{ }^{1}$, Anne Castles ${ }^{1}$, Saskia Kohnen ${ }^{1,2}$, Erin Banales ${ }^{1}$ \\ ${ }^{1}$ Department of Cognitive Science, ARC Centre of Excellence in Cognition and its Disorders, Macquarie University, Sydney, New South Wales, Australia \\ 2 Department of Cognitive Science, ARC Centre of Excellence for Cognition and its Disorders, Macquarie University, NSW, Australia \\ Corresponding Author: Genevieve McArthur \\ Email address: genevieve.mcarthur@mq.edu.au
}

There is evidence that poor readers are at increased risk for various types of low selfconcept - particularly academic self-concept. However, this evidence ignores the heterogeneous nature of poor readers, and hence the likelihood that not all poor readers have low self-concept. The aim of this study was to better understand which types of poor readers have low self-concept. We tested 77 children with poor reading for their age for four types of self-concept, four types of reading, three types of spoken language, and two types of attention. We found that poor readers with poor attention had low academic selfconcept, while poor readers with poor spoken language had low general self-concept in addition to low academic self-concept. In contrast, poor readers with typical spoken language and attention did not have low self-concept of any type. We also discovered that academic self-concept was reliably associated with reading and receptive spoken vocabulary, and that general self-concept was reliably associated with spoken vocabulary. These outcomes suggest that poor readers with multiple impairments in reading, language, and attention are at higher risk for low academic and general self-concept, and hence need to be assessed for self-concept in clinical practice. Our results also highlight the need for further investigation into the heterogeneous nature of self-concept in poor readers. 
1

2

3

4

5

6

7

8

9

10

11

12

13

14

15

16

17

18

19

\section{Low self-concept in poor readers: prevalence, heterogeneity, and risk}

Genevieve McArthur, Anne Castles, Saskia Kohnen, and Erin Banales

Department of Cognitive Science, ARC Centre of Excellence in Cognition and its Disorders, Macquarie University Cognition Clinic for Reading Macquarie University, Sydney, Australia 


\section{Abstract}

21 There is evidence that poor readers are at increased risk for various types of low self-concept -

22 particularly academic self-concept. However, this evidence ignores the heterogeneous nature of

23 poor readers, and hence the likelihood that not all poor readers have low self-concept. The aim of

24 this study was to better understand which types of poor readers have low self-concept. We tested

2577 children with poor reading for their age for four types of self-concept, four types of reading,

26 three types of spoken language, and two types of attention. We found that poor readers with poor

27 attention had low academic self-concept, while poor readers with poor spoken language had low

28 general self-concept in addition to low academic self-concept. In contrast, poor readers with

29 typical spoken language and attention did not have low self-concept of any type. We also

30 discovered that academic self-concept was reliably associated with reading and receptive spoken

31 vocabulary, and that general self-concept was reliably associated with spoken vocabulary. These

32 outcomes suggest that poor readers with multiple impairments in reading, language, and attention

33 are at higher risk for low academic and general self-concept, and hence need to be assessed for

34 self-concept in clinical practice. Our results also highlight the need for further investigation into

35 the heterogeneous nature of self-concept in poor readers. 


\section{Low self-concept in poor readers: prevalence, heterogeneity, and risk}

38 Sixteen percent of children have reading skills that fall below the average range for their age, and

395 percent of children have significant and severe reading difficulties (Shaywitz, Escobar,

40 Shaywitz, Fletcher, \& Makuch, 1992). These children's reading difficulties vary in aetiology.

41 Some children struggle to learn new skills in general ("general learning difficulty"), while others

42 struggle to learn to read despite adequate instruction and the ability to learn new skills in general

43 ("development dyslexia"; "specific learning disability”). These children's reading difficulties

44 also vary in type. Some poor readers have problems with learning to read words accurately

45 (reading accuracy), some with learning to read words fluently (reading fluency), some with

46 understanding what they read (reading comprehension), and many poor readers have different

47 combinations of these problems (Stuart \& Stainthorpe, 2016).

We have known for quite some time that poor reading puts children at higher risk for

academic failure (Herbers et al., 2012; Smart, Prior, Sanson, \& Oberklaid, 2001). However, we

50

51

52

53

54

are only just starting to understand how poor reading affects children's emotional health. In the current study, we focus on poor readers' self-concept, which can be defined as a "person's perceptions of him- or herself. These perceptions are formed through experience with and perceptions of one's environment. They are influenced especially by evaluations by significant others, reinforcements, and attributions for one's own behaviour" (Marsh \& Shavelson, 1985; p. 107). Positive self-concept is associated with numerous important facets of life, such as academic achievement (Marsh \& Craven, 2006), economic success and health (OECD, 2003), emotional adjustment (Donahue, Robins, Roberts, \& John, 1993), coping (Shirk, 1988), and happiness (Harter, 1990).

Self-concept typically refers to a person's perceptions of her- or himself in a particular 
60 domain (e.g., academic, social, parent-home, or physical; Cole et al., 2001; Harter, Whitesell, \&

61 Junkin, 1998; Marsh \& Seaton, 2013). This contrasts with self-esteem, which has been defined as

62 “one's global sense of well-being as a person” (p. 148, Zeleke, 2004). In the context of an

63 academic domain such as reading, it is important to discriminate between different domains of

64 self-concept, as well as between self-concept and self-esteem, since academic achievement

65 appears to have a reciprocal relationship with some domains (i.e., academic self-concept) and not

66 others (i.e., non-academic domains), and no reciprocal relationship with self-esteem at all (Marsh

$67 \&$ Martin, 2011).

68 Around two-dozen studies have tested poor readers for at least one domain of self-concept,

69 including academic self-concept (Alexander-Passe, 2006; Terras, Thompson, \& Minnis, 2009),

70 social self-concept (e.g., Martinez \& Semrud-Clikeman, 2004; Snowling, Muter, \& Carroll,

71 2007), athletic self-concept (e.g., Boetsch, Green, \& Pennington, 1996; Frederickson \& Jacobs,

72 2001), physical self-concept (e.g., Humphrey \& Mullins, 2002; Casey, Levy, Brown, \& Brooks-

73 Gunn, 1992), behavioural self-concept (e.g., Frederickson \& Jacobs, 2001; Murray, 1978),

74 parental self-concept (e.g., Thomson \& Hartley, 1980; Westervelt, Johnson, Westervelt, \&

75 Murrill, 1998), reading self-concept (e.g., Bull, 2007; Morgan, Fuchs, Compton, Cordray, \&

76 Fuchs, 2008), and practical self-concept (e.g., Polychroni, Koukoura, \& Anagnostou, 2006). Of

77 these domains, it is academic self-concept that appears to be most reliably impaired in poor

78 readers (Alexander-Passe, 2006; Boetsch et al., 1996; Casey et al., 1992; Frederickson \& Jacobs,

79 2001; Humphrey \& Mullins, 2002; Murray, 1978; Snowling et al., 2007; Terras et al., 2009;

80 Thomson \& Hartley, 1980; Westervelt et al., 1998). For example, Taylor, Hulme, and Welsh

81 (2010) tested twenty-six 8- to 12-year-old poor readers in mainstream classrooms for their self-

82 concept in scholastic competence (academic self-concept), social acceptance, athletic 
83 competence, physical appearance, and behavioural conduct. Compared to 23 children with no

84 learning disability, the poor readers only had poor scores for academic self-concept. Similarly,

85 Snowling et al. (2007) tested twenty-one 12- to 13-year- old poor readers for their perceived

86 scholastic competence (academic self-concept), social competence, and athletic competence.

87 They too found that, compared to age-matched typical readers $(\mathrm{N}=17)$, poor readers scored

88 poorly on academic self-concept alone. Thus, studies of self-concept in poor readers to date have

89 produced mixed findings, suggesting that poor readers are at increased risk for various types of

90 low self-concept, particularly low academic self-concept.

91 Unfortunately, studies of self-concept in poor reader to date have not considered which

92 types of poor readers are at increased risk for low self-concept - academic or otherwise. This

93 knowledge is important because it may reveal why previous studies have found mixed evidence

94 for poor self-concept in poor readers. The absence of information about the heterogeneity in self-

95 concept in poor readers is surprising given that (1) poor readers are known to be a highly

96 heterogeneous population, and (2) we have yet to discover a single impairment - emotional,

97 genetic, neurological, cognitive, environmental, or behavioural - that is present in all poor

98 readers. It is therefore likely - if not a surety - that not all poor readers have low self-concept.

99 Yet, to our knowledge, no study has attempted to understand which types of poor readers are

100 more likely to have poor self-concept.

101 There are three areas of cognition that poor readers reliably vary in type: their reading,

102 their language, and their attention. Regarding their reading, and as mentioned above, some poor

103 readers have problems with reading accuracy, some with reading fluency, some with reading

104 comprehension, and many have different combinations of these problems. To complicate things

105 further, within the domain of reading accuracy alone, some children have problems with learning 
106 to read words via phonological recoding (the ability to decode words using the letter-sound rules),

107 some via visual word recognition (i.e., the ability to recognise whole words from a mental store,

108 or lexicon, of written words), and some via both phonological recoding and sight word reading

109 (McArthur et al., 2013; Stuart \& Stainthorpe, 2016). Thus, poor readers vary considerably in the

110 nature of their reading impairments. This variance can be captured via tests of phonological

111 recoding accuracy, visual word recognition accuracy, reading fluency, and reading

112 comprehension.

113 Regarding spoken language, there is abundant evidence that some (but not necessarily all)

114 poor readers have concomitant impairments in their spoken language abilities (Bishop \&

115 Snowling, 2004; Catts, Adolf, Hogan, \& Weismer, 2005; Eisenmajer et al., 2005; Fraser et al.,

116 2010; McArthur et al., 2000; Rispens \& Been, 2008). After reviewing this evidence, Bishop and

117 Snowling (2004) proposed that language impairments in poor readers might be categorized as

118 either phonological in nature (e.g., phonological representations, phonological segmentation,

119 phonological memory) or non-phonological in nature (e.g., semantics and syntax). They

120 suggested that phonological impairments in poor readers might be indexed using nonword

121 repetition tasks, and that non-phonological impairments could be indexed using receptive and

122 expressive measures of vocabulary knowledge.

123 Regarding attention, previous studies have reported that poor readers, as a group, are more

124 likely to have inattention or hyperactivity than typical readers (e.g., Gilger, Pennington, \&

125 DeFries, 1992; Shaywitz, Fletcher, \& Shaywitz, 1995; Willcut \& Pennington, 2000). Similarly,

126 there is evidence that some (but not all) children diagnosed with attention deficit disorder (i.e.,

127 around 50\%) have poor reading relative to children with typical attention (Dykman \& Ackerman,

128 1991; Semrud-Clikeman et al., 1992). These studies indicate that, like reading and language, 
129 poor readers vary in their levels of attention. Further, these differences can be measured via tests 130 of inattention and hyperactivity.

131 In sum, the evidence to date suggests that poor readers may be at increased risk for various

132 types of low self-concept - most particularly academic self-concept. However, this evidence

133 overlooks the fact that poor readers represent a highly varied population - particularly in terms

134 of their reading, their spoken language, and their attention. It is therefore likely that only some

135 poor readers have low self-concept. The specific aim of this study was to better understand which

136 types of poor readers have low self-concept by conducting three analyses. In the first, we

137 estimated the prevalence of low scores in poor readers for four types of low concept (academic,

138 general, home, and social). From the existing evidence discussed above, we predicted that our

139 sample of poor readers would have a disproportionately high number of low scores for their

140 academic self-concept but not their general, home, or social self-concept.

141 In the second analysis, we divided our poor readers into groups that had either (1) poor

142 reading alone, (2) poor reading and poor spoken language, (3) poor reading and poor attention, or

143 (4) poor reading, poor spoken language, and poor attention. We compared these groups for

144 scores on the four self-concept scales. Previous research has found low self-concept in people

145 with specific language impairment (Carroll \& Iles, 2006; Carroll, Haughan, Goodman, \& Mltzer,

146 2005; Lindsay \& Dockrell, 2000) and people with poor attention (Maughan \& Carroll, 2006;

147 Treuting \& Hinshaw, 2001). There is also evidence that poor readers with concomitant problems

148 with spoken language or attention are at higher risk for more severe cognitive deficits than poor

149 readers with typical language and attention (Eisenmajer et al. 2005; Fraser et al., 2010; McArthur

150 \& Castles, 2013; McArthur \& Hogben, 2001; Willcut et al., 2001). Combining this evidence, we

151 tentatively predicted that poor readers with two comorbid problems (i.e., poor language and 
152 poor attention) would have more problems with self-concept than poor readers with one

153 comorbid problem (i.e., poor language or poor attention), who would have more problems with

154 self-concept than poor readers with typical language and attention.

155 In the final analysis, we used correlation coefficients to determine which types of reading

156 ability (phonological recoding accuracy, visual word recognition accuracy, reading fluency,

157 reading comprehension), spoken language ability (phonological processing, spoken vocabulary

158 knowledge), or attention (inattention, hyperactivity) might be reliably related to specific types of

159 self-concept. To our knowledge, the specific relationships between different types of reading,

160 language, attention and self-concept have never been examined before, and hence the outcomes

161 of this analysis were necessarily exploratory.

162

\section{Methods}

163 Informed consent and ethics approval

164 The University Human Research Ethics Committee approved the methods of this study

165 (5201200852). The parents of all children gave informed written consent for their child to

166 participate in the study. In addition, children gave their informed verbal consent to participate in

167 the study.

168 Participants

169 This study recruited 77 children with poor reading recruited from the general community.

170 The study was advertised via newspaper advertisements, via a Kids' Science Club, and via letters

171 to schools. All children were aged from 9 to 12 years since this was the appropriate age-range for

172 the self-concept subtests (see Self-concept Measures below). In addition, they scored at least 1

173 SD below the age-expected for either phonological recoding or visual word recognition (see

174 Screening Tests below); spoke English as their first language; and had no history of neurological 
175 or sensory impairment, as indicated on a background questionnaire. While we measured

176 children's non-verbal IQ for information (see Screening Measures and Table 1), we did not

177 exclude children based on non-verbal IQ scores since nonverbal IQ does not appear to predict the

178 ability to learn to read (Gresham \& Vellutino, 2010; Siegel, 1989). The children attended a

179 variety of public and private schools. Given the absence of strict regulations about how reading

180 should be taught in the school system, our sample would have received a mixture of reading

181 instruction, ranging from predominantly phonics instruction, to a mixture of phonics and sight

182 word instruction, to "whole-word" instruction, which focuses primarily on meaning and reading

183 strategies.

184 In line with previous studies (e.g., Alexander-Passe, 2006; Bull, 2007; Terras et al., 2009;

185 Westervelt et al., 1998), this study did not recruit a control group because all tests were normed 186 on large samples of typically-developing children who would have produced more reliable data

187 than an aged-matched, sized-matched control group recruited for this study (i.e., $\mathrm{N}=77$ across 9-

$188,10-, 11-$, and 12-year-old age groups). Further, in line with most standardised assessment, this

189 study considered scores from -1 SD to +1 SD as representative of the average range. Standard

190 scores, scaled scores, or z scores below -1, 85, or 7 (respectively) - which represent the lowest

$19115.9 \%$ of scores in a normal distribution - were considered to be "low" (with regards to self-

192 concept) or "poor" (with regards to reading or language). In addition, we considered z scores

193 from -1 to -0.5 , standard scores from 85 to 92 , and scaled scores from 7 to 8 to be "low-average".

194 And we considered $\mathrm{z}$ scores from -0.51 to +1 , standard scores from 86 to 115 , and scaled scores

195 from 9 to 13 to be "average".

196 The vast majority of children produced complete data sets. One child's parents did not

197 complete the inattention and hyperactivity questionnaire, and hence that child could not be 
198 assigned to a group for the second analysis, and they did not contribute to correlation coefficients

199 including inattention and hyperactivity in the third analysis. Six children did not complete the

200 nonverbal intelligence test. Since this test was used to get a general sense of the sample, and was

201 not included in any of the analyses in this study, the absence of this data had little or no effect on

202 the validity of the outcomes.

203 Table 1 provides descriptive statistics for the test scores of the 77 poor readers in this study.

204 These statistics indicated that this sample of children had, on average, poor scores for

205 phonological recoding and visual word recognition; low-average scores for reading fluency and

206 reading comprehension, academic and general self-concept, as well as expressive vocabulary;

207 and average scores for nonverbal IQ, home and social self-concept, as well as phonological

208 processing and receptive vocabulary (see sections below for descriptions of tests). Their scores

209 for inattention and hyperactivity fell well below cut-offs for clinical significance (1.78 for and

210 1.44, respectively). Thus, overall, our sample of poor readers had marked, but not unusually

211 severe, reading problems. Examination of SD, minimum and maximum values further indicated

212 that some poor readers had concomitant deficits in their spoken language and attention. Such a

213 sample is representative of English-speaking poor readers found in mainstream primary-school

214 classrooms in the UK, US, and Australia.

Please insert Table 1 about here

\section{Procedure}

Each child in our sample was invited to the University to complete the Screening, Self-

218 concept, Reading, and Language Measures (see below) individually in a quiet testing room. The

219 measures represented part of a larger test battery that took 2-3 hours to complete, depending

220 upon the child's age, ability, and personality. The tests were administered in a fixed order that 
221 separated longer tests (e.g., non-verbal IQ) with shorter tests (reading fluency). Children were

222 given positive reinforcement and encouragement throughout the testing session regardless of

223 their level of achievement. At the completion of each test, a child was given to sticker to put on a

224 progress chart to help them track their achievement and progress. They were also given

225 numerous breaks, during which they played games with the tester or had a snack (approved by

226 parents). With parental permission, children were rewarded for their efforts with $\$ 30$. Parents

227 completed the Attention Measures at home or at the University while their child completed their

228 tests. Their travel costs were reimbursed with $\$ 10-15$, depending upon distance travelled to the

229 University.

\section{Screening measures}

231 Phonological recoding and visual word recognition. We tested these two skills using

232 the Castles and Coltheart $2^{\text {nd }}$ Edition $(\mathrm{CC} 2)$ Nonword subtest and the CC2 Irregular Word

233 subtest, respectively (Castles et al., 2009). The CC2 comprises three lists: 40 nonwords (e.g.,

234 GRENTY), 40 irregular words (e.g., TOMB), and 40 regular words (e.g. STENCH). The stimuli

235 within each list are presented in order of increasing difficulty in an inter-mixed fashion (e.g.,

236 regular word 1, irregular word 1, nonword 1, nonword 2, irregular word 2, regular word 2,

237 irregular word 3, regular word 3, nonword 3, and so on). Stimuli within each list are presented

238 until a child makes five consecutive errors within that list. Items in other lists continue to be 239 presented until a child makes five consecutive errors within a list, or they reach the end of the 240 test. Scores for each list are $\mathrm{z}$ scores with a mean of 0 and SD of 1 . Internal consistency for this 241 test is .94 (Moore, Porter, Kohnen, \& Castles, 2012). 
243 the Kaufman Brief Intelligence Test $2^{\text {nd }}$ Edition (KBIT-2; Kaufman \& Kaufman, 2004). In each

244 trial, children are shown an incomplete picture matrix, and asked to select the missing portion

245 from four or six possible options. Scores are standard scores with a mean of 100 and an SD of

246 15. The split-half reliability for this subtest is .80 to .90 , and the test-retest reliability is .83 .

\section{Self-concept measures}

Self-concept was measured with the Culture Fair Self Esteem Inventory (3rd Edition) that was designed for children aged 9- to 12-years-old (CFSEI-3; Battle, 2002). It comprises four

250 subtests, one each for academic, general, home, and social self-concept. The CSFEI-3 comprises

25164 statements, which were each read aloud to the poor readers in this study. Each statement

252 referred to a child's self-concept in the academic domain (10 items; e.g., I am satisfied with my

253 schoolwork), general domain (14 items; e.g. Most boys and girls are better at doing things than

254 me), home domain (12 items; e.g. My family thinks I am important), and social domain (18

255 items; e.g. Boys and girls like to play with me). Each domain was measured using scaled scores

256 that had a mean of 10 and standard deviation of 3. Mean internal consistency and time sampling

257 reliability coefficients for the four domains range from .72 to .98 .

\section{Reading measures}

259 Reading accuracy. As described under Screening Measures above, we tested these two 260 skills using the CC2 Nonword subtest and the CC2 Irregular Word subtest, respectively (Castles 261 et al., 2009).

262 Reading fluency. We measured word reading fluency using the Sight Word subtest of the 263 widely-used Test of Word Reading Efficiency (TOWRE; Torgesen, Wagner, \& Rashotte, 1999). 264 In this subtest, children are asked to read a mix of regular and irregular words as quickly as they 
265 can within 45 seconds. The TOWRE was designed to produce standard scores with a mean of

266100 and standard deviation of 15 . In this study, we converted these standard scores into z scores

267 (with a mean of 0 and SD of 1) to make the reading fluency scores directly comparable to the

268 reading accuracy and reading comprehension $\mathrm{z}$ scores. The mean parallel form and test-retest

269 reliability coefficients for the TOWRE exceed .90.

270 Reading comprehension. This was assessed using the Test of Everyday Reading

271 Comprehension (TERC; McArthur et al., 2013). This includes 10 "everyday" reading stimuli,

272 such as a text message or a medicine label. For each stimulus, children are asked two literal

273 questions about the information in the text. Scores are $\mathrm{z}$ scores with a mean of 0 and standard

274 deviation of 1 . The parallel-form and inter-rater reliability of the TERC is .86 and .99,

275 respectively. The validity of the TERC is supported by a study by Wheldall and McMurtry

276 (2014) who reported that TERC scores in poor readers were statistically significantly and

277 strongly correlated $(\mathrm{r}=.71)$ with the widely-used reading comprehension subtest of the Neale

278 Analysis of Reading Ability (Neale, 1999), which uses short stories as text stimuli, rather then

279 everyday text stimuli.

280 Spoken language measures

281 Phonological processing. We assessed phonological processing with a nonword

282 repetition test: the standardized Neuropsychological Assessment (NEPSY) Repeating Nonwords 283 subtest (Korkman, Kirk, \& Kemp, 1998). In this test, children are asked to repeat 13 nonsense 284 words that increase in length (e.g., "ba-fee" to "skri-flu-na-fliss-trop"). Scores are scaled scores 285 with a mean of 10 and a SD of 3 . The mean test-retest reliability of this subtest for school-aged 286 children is .74 (Brooks, Sherman, \& Strauss, 2010).

287 Receptive vocabulary. To test receptive vocabulary, we used the Peabody Picture 
288 Vocabulary Test $4^{\text {th }}$ Edition (PPVT-4; Dunn \& Dunn, 2007). For each item, children are shown

289 four pictures and asked to point to the picture that is named by the tester. Scores are standard

290 scores with a mean of 100 and an SD of 15 . The test-retest, split-half, and parallel-form

291 reliability coefficients of this test are .92 to $.96, .89$ to .97 , and .87 to .93 , respectively.

292 Expressive vocabulary. We tested expressive vocabulary using the standardized Picture

293 Naming subtest from the Assessment of Comprehension and Expression 6-11 (ACE; Adams,

294 Cooke, Crutchley, Hesketh, \& Reeves, 2001). Children are asked to name the object in each of

29525 pictures. Scores are scaled scores with a mean of 10 and SD of 3.

\section{Attention measures}

297 Inattention. This was measured with the Swanson, Nolan, and Pelham (4 ${ }^{\text {th }}$ Edition;

298 SNAP-4; Swanson, Sandman, Deutsch, \& Baren, 1983), which is a parent questionnaire that 299 comprises nine descriptions of a child's behaviour that index "inattention". Mean and SD data

300 for girls and boys aged 5 to 11 years published by Bussing et al. (2008) were used to calculate 301 age- and sex-appropriate $\mathrm{z}$ scores for each child, which had a mean of 0 and SD of 1 . Internal 302 reliability for the SNAP overall is .94 (parents) and .97 (teachers; Bussing et al., 2008). The raw 303 score for clinical significance is 1.78 .

304 Hyperactivity. This was also measured with the SNAP-4, which includes nine 305 descriptions that index "hyperactivity-impulsivity". Again, mean and SD data for girls and boys 306 aged 5 to 11 years, published by Bussing et al. (2008), were used to calculate age- and sex307 appropriate $\mathrm{z}$ scores for each child. The raw score for clinical significance is 1.44 .

\section{Data analysis}

The data analysis comprised three steps. As outlined in the Introduction, the aim of the first

310 step was to determine if a disproportionately high number of low scores for their academic self- 
311 concept but not their general, home, or social self-concept. We estimated the prevalence of low

312 scores in our poor readers for four types of self-concept (academic, general, home, and social).

313 Prevalence of low scores was measured as the percentage of scores lower than $-1 \mathrm{SD}(\mathrm{ScS}=7)$

314 on each self-concept scale. To test if prevalence of low scores was atypical for a normal

315 distribution, we used one-sample t-tests to compare each set of self-concept scores to the mean

316 (M) expected for a typical population $(\mathrm{ScS}=10)$. We used one-tailed tests of significance to

317 determine if low scores were statistically reliable $(\mathrm{p}<.05)$, rather than typical two-tailed tests of

318 significance, because we had a clear prediction about direction of scores (i.e., low in poor

319 readers).

320 The outcomes of the first step in the analysis suggested that distributions of scores for at

321 least two of the self-concept measures (academic and general) might differ significantly from a

322 normal distribution. This was confirmed by Levene Tests for Normality, which revealed that, in

323 fact, the distribution of scores for 10 of the 13 variables in this study differed significantly from a

324 normal distribution. Thus, non-parametric statistics were used in the second and third analyses.

325 The aim of the second step of the analysis was test if poor readers with two comorbid

326 problems have more problems with self-concept that poor readers with one comorbid problem,

327 who would have more problems with self concept with poor readers with poor reading alone. We

328 therefore divided poor readers into four groups who either had poor reading alone, poor reading

329 and poor spoken language, poor reading and poor attention, or poor reading and poor spoken

330 language and poor attention. After ensuring that the four groups differed only in their spoken

331 language and attention (i.e., not their reading), we used One-Sample Wilcoxon Signed Rank

332 Tests and Kruskal-Wallis Tests to compare their median scores for four types of self-concept

333 (academic, general, home, and social) to a typical population and to each other, respectively. 
334 Again, because we had a clear prediction about direction of scores (i.e., low in poor readers), we

335 used one-tailed tests of significance $(\mathrm{p}<.05)$.

336 In the third step of the analysis, we used Spearman Rho Rank Correlation Coefficients to

337 determine which types of reading ability (phonological recoding accuracy, visual word

338 recognition accuracy, reading fluency, reading comprehension), spoken language ability

339 (phonological processing, spoken vocabulary knowledge), or attention (inattention,

340 hyperactivity) were reliably related to different domains of self-concept (academic, general,

341 home, and social). As outlined in the Introduction, this analysis was exploratory. We made no

342 predictions about direction of outcomes and so used two-tailed tests of significance $(\mathrm{p}<.05)$.

\section{Results}

344 Step 1: Prevalence of low academic, general, social, and home self-concept score in poor 345 readers

346 Compared to a typical population in which $15.9 \%$ of scores fall below $-1 \mathrm{SD}$, our sample 347 of poor readers had an unusually high rate of low scores for academic self-concept $(19 / 77=$ $34825 \% ; M=8.53 ; S D=2.84 ; t(76)=4.14, p<.001)$ and general self-concept $(23 / 77=30 \% ; M=$ $3498.23 ; S D=2.98 ; t(76)=5.20, p<.001)$. In contrast, the percentage of poor readers with low 350 scores for home self-concept $(7 / 77=9 \% ; M=10.31 ; S D=2.62 ; t(76)=1.04, p=.15)$ and social 351 self-concept $(15 / 77=19 \% ; M=9.62 ; S D=3.06 ; t(76)=1.08, \mathrm{p}=.11)$ were not different to that 352 expected for a typical population.

353 Step 2: Comparing self-concept in poor readers, poor readers with language impairment, 354 poor readers with poor attention, and poor readers with language impairment and poor 355 attention 
We divided our sample of poor readers into four groups: those with poor scores (i.e.,

357 lower than $1 \mathrm{SD}$ ) on at least one measure of (1) reading, but no measure of language or attention

358 (Reading group), (2) reading and spoken language, but no measure of attention (Reading +

359 Language group), (3) reading and attention, but no measure of language (Reading + Attention

360 group), or (4) reading and spoken language and attention (Reading + Language + Attention

361 group). As outlined above, before comparing these four groups for self-concept scores, we

362 needed to determine whether the poor readers in each group differed in their reading profiles (i.e.,

363 in addition to differing in their language and attention profiles). Figure 1 shows the median

364 reading scores (with upper and lower quartiles) of the four groups. The horizontal line in this

365 figure represents the median level expected for each child's age (i.e., a z score of 0). Any median

366 (short black horizontal line) within a patterned box that fell below the horizontal line indicates a

367 distribution of scores that was reliably poorer than the mean level expected for age.

Please insert Figure 1 about here

The four groups had similar medians for phonological recoding and visual word comprehension: $r_{s}=42, p<.001$; reading fluency: $\left.r_{s}=.38, p=.001\right)$ and spoken expressive vocabulary (reading comprehension $r_{s}=.33, p=.002$; reading fluency: $r_{s}=.29, p=.005$ ).

374 Nevertheless, Kruskal-Wallis tests revealed that there was no significant difference between the 375 four groups on any of the reading tests: phonological recoding $(H=3.83, p=.14)$, visual word 376 recognition $(H=4.56, p=.10)$, reading fluency $(H=4.52, p=.10)$, and reading comprehension $377(H=3.93, p=.14)$. 
379 turned to their self-concept. Figure 2 shows the median self-concept scores (with upper and

380 lower quartiles) of the four groups defined above, along with the median level expected for each

381 child's age (i.e., a scaled score of 10).

382

383

384

385

386

387

388

389

390

391

392

393

394

395

396

397

398

399

400

401

Please insert Figure 2 about here

One-Sample Wilcoxon Signed Rank Tests were used to compare each distribution of selfconcept scores in each group to the median score expected for a child's age (i.e., $\mathrm{ScS}=10$ ). The associated medians $(M d)$, means $(M)$, standard deviations $(S D)$, Wilcoxon Signed Rank Test values $(Z), \mathrm{p}$ values $(p)$, and effect size values $(r)$ are shown in Table 2 for each group for each type of self-concept. Statistically significant differences are marked in grey. Effect size $r$ values of $0.1,0.3$, and 0.5 were considered small, moderate, and large, respectively.

Please insert Table 2 about here

The results revealed that (1) in the Reading Group, no type of self-concept fell significantly below the age-expected median (i.e., 10); (2) in the Reading + Language Group, academic self-concept and general self-concept fell significantly below the age-expected median; (3) in the Reading + Attention Group, academic self-concept fell significantly below the ageexpected median; (4) in the Reading + Language + Attention group, academic and general selfconcept fell below the age-expected median. All statistically significant effects were large in size. It is noteworthy that the Reading group had higher-than-expected median scores for home and social self-concept. Because we used one-tailed significance tests to detect low scores, we cannot speak to the reliability of the higher home and social self-concept scores in this study.

We also used independent samples Kruskal-Wallis Tests to compare across groups for each type of self-concept. There was no significant difference between the groups for academic $(H=2.55, p=.24)$ or home $(H=4.47, p=.11)$ self-concept. There was a significant difference 
402 between groups for general self-concept $(H=12.72, p=.002)$. Post-hoc Mann-Whitney U tests

403 revealed that the two groups with language impairment had lower general self-concept than the

404 Reading group (Reading + Language Group: $Z=-3.51, p<.001$; Reading + Language +

405 Attention: $Z=-1.96, p=.002)$. Thus, the presence of low general self-concept appeared to be

406 associated with the presence of poor spoken language rather than poor reading or poor attention.

407 The Kruskal-Wallis Tests also revealed a significant difference between groups for social 408 self-concept $(H=8.60, p=.02)$. Post-hoc Mann-Whitney U tests revealed that the Reading

409 Group had significantly higher scores than the Reading + Language group $(Z=2.32, p=.01)$

410 and the Reading + Language + Attention group $(Z=2.52, p=.005)$. Since the latter two groups

411 had near-median social self-concept scores for their age, these group effects were driven by the

412 unusually high scores of the Reading group, the reliability of which could not be ascertained by

413 this study due to the use of one-tailed significance tests designed to detect low scores. Thus, this

414 group effect was not considered further.

415 Step 3: The relationship between poor readers' self-concept, reading, spoken language, and 416 attention

417 Since Step 2 revealed that some types of poor readers have reliably poor scores for 418 academic self-concept (i.e., if they have poor spoken language or attention) or for general self419 concept (i.e., if they have poor spoken language), we used Spearman Rho Rank Correlation 420 Coefficients to explore which types of reading ability (phonological recoding accuracy, visual 421 word recognition accuracy, reading fluency, reading comprehension), spoken language ability 422 (phonological processing, receptive vocabulary, expressive vocabulary), or attention (inattention, 423 hyperactivity) might be reliably associated with these two types of self-concept. The coefficients 424 are shown in Table 3 (Note that a similar table including correlation coefficients for home and 
425 social self-concept is included in the Appendix for interested readers). In line with Cohen (1992),

426 correlations of $0.1,0.3$, and 0.5 were considered small, moderate, and large, respectively. As

427 outlined in the Introduction, we did not have clear predictions for the third step of the analysis,

428 which was exploratory in nature. We therefore used a more conservative criterion for statistical

429 significance the previous analyses, with $p<.05$. Statistically significant coefficients in Table 3

430 are marked in grey.

431

432

433

434

435

436

437

438

439

440

441

442

443

444

445

446

447

Please insert Table 3 about here

The coefficients in Table 3 suggest four interesting trends: (1) most statistically

significant correlation coefficients were moderate in size, with only two moderate-to-large in size; (2) neither academic nor general self-concept were reliable correlated with phonological processing, inattention, or hyperactivity in poor readers; (3) academic self-concept was reliably associated with all reading measures and one spoken language measure (receptive vocabulary); and (4) general self-concept correlated with measures that taxed receptive or expressive vocabulary - including the reading test most strongly correlated with vocabulary (i.e., reading comprehension: $\left.r_{s}=.42, p<.001\right)$ and expressive vocabulary $\left(r_{s}=.33, p=.003\right)$. This suggests that general self-concept is related to spoken vocabulary rather than reading per se. In line with this suggestion, there was an almost non-existent relationship between general self-concept and phonological recoding $\left(r_{s}=.01, p=.94\right)$, which itself had very weak relationships with receptive vocabulary $\left(r_{s}=.17, p=.15\right.$ and expressive vocabulary $\left(r_{s}=.05, p=.66\right)$.

\section{Discussion}

The aim of this study was to better understand which types of poor readers have low selfconcept. We addressed this aim in three analyses. Below, we outline the outcomes of each analysis, and whether the outcomes supported our predictions based on existing evidence (if any). 
448 Analysis 1: Prevalence of low academic, general, home, and social self-concept in poor 449 readers

450 We estimated the prevalence of low scores in our poor readers for four types of self451 concept (academic, general, home, and social) to test the prediction that poor readers would have 452 a disproportionately high number of low scores for their academic self-concept but not their 453 general, home, or social self-concept. Compared to a typical population, our poor readers had 454 significantly higher rates of low scores for academic self-concept and general self-concept but 455 not home self-concept or social self-concept. This supports our prediction that academic self456 concept would be low in poor readers, but rebuts our prediction that general self-concept, along 457 with home and social self-concept, would be typical in poor readers. These findings support 458 previous studies that have reported that poor readers have low academic self-concept (e.g., 459 Snowling et al., 2007; Terras et al., 2009;); low general self-concept (Riddick, 1999); typical 460 home self-concept (e.g., Alexander-Passe, 2006; Westervelt et al., 1998); and typical social self461 concept (e.g., Terras et al., 2009; Snowling et al., 2007). In doing so, our findings simultaneously

462 fail to support a few previous studies that have found poor readers have typical academic self463 concept (e.g., Alexander-Passe, 2006); typical general self-concept (Westervelt et al., 1998); low 464 home self-concept (Thomson \& Hartley, 1980); and low social self concept (Boetsch et al., 465 1996). Considered together, the weight of current evidence suggests that poor readers are at 466 higher risk for academic and general self-concept but not home or social self-concept. It is 467 noteworthy that this mixed support for different types of low self-concept in poor readers is 468 conducive with the idea that not all poor readers have low self-concept.

469 Analysis 2: Comparing self-concept in poor readers with and without poor language and/or 470 attention 
471 We divided our poor readers into four groups (Reading, Reading + Language, Reading +

472 Attention, Reading + Language + Attention) to test the prediction that poor readers without

473 concomitant problems with spoken language or attention would have less severe problems with

474 self-concept than poor readers with poor spoken language or poor attention, who would have less

475 severe problems than poor readers with problems with both spoken language and attention.

476 Again, the results partially supported our prediction. Children with poor reading alone did not

477 have reliably low scores in any domain of self-concept. As predicted, children with either poor

478 spoken language or poor attention had greater problems with self-concept than poor readers

479 without these problems, with atypically low scores for their age for academic self-concept

480 (Reading + Language, Reading + Attention) and general self-concept (Reading + Language

481 group). Contrary to prediction, poor readers with both poor spoken language and poor attention

482 did not have poorer self-concept than those either a problem with spoken language or attention.

483 Indeed, they looked similar to children in the Reading + Language double deficit group, with

484 atypically low scores for both academic self-concept and general self-concept. Thus, it was the

485 presence of a deficit concomitant with poor reading that seemed to determine if academic self-

486 concept was impaired in poor readers, and it was the presence of a spoken language problem that

487 seemed to determine if general self-concept was impaired in poor readers.

488 These findings suggest, for the first time, that whether or not a poor reader has poor self-

489 concept depends on whether they have a comorbid problem with language or attention, and that

490 the type of self-concept problem that they have will depend on the type of comorbid problem that

491 they have. This suggestion offers a potential explanation for the mixed outcomes of previous

492 studies of self-concept in poor readers. To wit, whether or not a particular study finds evidence

493 for low self-concept in poor readers will depend on an interaction between the type of poor 
494 reader recruited for the study (e.g., with comorbid difficulties with language, comorbid

495 difficulties with attention, no comorbid difficulties) and the type of self-concept tested by the

496 study (e.g., academic self-concept, general self-concept, home self-concept). Unfortunately, it is

497 difficult to test the validity of this hypothesis at this point in time because very few studies have

498 assessed and report the spoken language and attention abilities of participants. The notable

499 exception is Snowling et al. (2007) who reported that their poor readers had verbal IQ scores (a

500 broad index of spoken language ability) and attention abilities below the average range. In line

501 with the outcomes of the current study, these poor readers had poor academic self-concept.

502 Analysis 3: Identifying which types of reading, language, and attention correlate with 503 academic and general self-concept

504 We used correlation coefficients to determine which types of reading problems, spoken

505 language problems, and attention problems, were reliably associated academic and general self-

506 concept. As noted in the Introduction, such relationships have never been examined before

507 within a group of poor readers, and hence no a priori predictions could be made. One key trend

508 in the outcomes was that academic self-concept was reliably associated with multiple measures -

509 specifically, all the reading measures and one language measure (receptive vocabulary). In line

510 with previous research, this suggests that problems with reading (e.g., Alexander-Passe, 2006;

511 Terras et al., 2009) or spoken language (Carroll \& Iles, 2006; Carroll et al., 2005; Lindsay \&

512 Dockrell, 2000) may put a person at higher risk for low academic self-concept. The outcomes of

513 the current study further suggest that this risk may only reach significant levels in poor readers

514 who have a comorbid deficit in another cognitive domain such as language.

515 Another interesting trend in the coefficients was that general self-concept only correlated

516 with measures that taxed receptive or expressive vocabulary to some degree, including reading 
517 comprehension, reading fluency, and visual word recognition. Thus, poorer receptive or

518 expressive vocabulary skills may put a child at higher risk for low general self-concept, but poor

519 reading ability and poor attention per se do not.

520 Theoretical implications

$521 \quad$ Understanding which types of poor readers have low self-concept is useful for developing

522 a more complete theory about why there might be association between poor reading and poor

523 self-concept. At this point in time, theoretical explanations about the mechanisms linking poor

524 reading and low self-concept are underspecified. For example, it has been proposed that (1) poor

525 reading leads to low self-concept, (2) low self-concept leads to poor reading, (3) a third factor

526 causes both poor reading and low self-concept, or (4) there is a two-way interaction in which

527 poor reading causes low self-concept and then low self-concept in turn causes poor reading (e.g.,

528 Battle, 2002; Riddick, 2010). These theoretical accounts do not identify the mechanisms that

529 might form a causal chain linking poor reading to low self-concept (or vice versa).

530 The outcomes of this study make four tentative suggestions about the nature of these

531 mechanisms. First, finding only modest correlation coefficients between reading and some

532 domains of self-concept (academic and general) could be taken to suggest that the link between

533 poor reading and poor self-concept is not a close nor direct one. Rather, it may be the case that

534 the causal chain linking reading to self-concept, if one exists, comprises numerous links, each of

535 which may moderate (i.e., reduce) the overall strength of the relationship between the end points

536 of the chain (i.e., reading and self-concept). Second, finding that children with poor reading

537 alone had no problems with self-concept might be interpreted as suggesting that poor reading per

538 se may not be enough to trigger a chain of causal events leading to poor academic self-esteem.

539 Third, the finding that children with poor reading plus poor language or poor attention have poor 
540 academic self-concept raises the possibility that academic self-concept is at risk only when poor

541 reading is paired with another cognitive deficit. Fourth, finding that poor readers with poor

542 spoken language have poor general self-concept suggests that spoken language impairment may

543 have a relationship with general self-concept that is independent of reading impairment.

544 Considering these four possibilities together, we cautiously hypothesise that if a child

545 "only" has a reading impairment, they may not be at risk for low self-concept because their

546 parents and friends view their specific reading impairment as a unique exception to their child's

547 overall academic, general, home, or social abilities. This may minimize the amount of negative

548 feedback that a child receives about her- or himself, and hence preserve their self-concept in all

549 domains. However, if a child has poor reading in conjunction with another deficit - such as a

550 problem with spoken language or attention, or perhaps mathematics, writing, or motor co-

551 ordination - their parents and friends may form a more negative view about that child's academic

552 or general ability, and hence the child may receive negative feedback from significant others

553 about their ability to succeed at school or in life in general. This may negatively affect their own

554 perception of their academic or general abilities, and hence result in lower academic or general

555 self-concept. The idea that children with multiple impairments are at higher risk for low self-

556 concept is consistent with cumulative risk models of developmental disorders which suggest that

557 while a single risk factor (e.g., poor reading) may increase a child's propensity for a cognitive,

558 environmental, socio-emotional or physical health problem, this impairment may only reach a

559 significant or clinical level when that single risk factor is paired with at least one other risk factor

560 (Aro et al., 2009; Dilnot, Hamilton, Maughan, \& Snowling, 2016).

\section{Clinical implications}

562 As well as providing some potential theoretical insights, the outcomes of the current study 
563 hint at how poor readers' self-concept might be assessed and treated in clinical practice. First and

564 foremost, if a poor reader is old enough to complete a self-concept test reliably, our results

565 suggest that they might be tested for their self- concept in the academic and general domains.

566 Given the individual differences in self-concept discovered in this study, one cannot presume

567 that a poor reader will, or will not, be at risk for low self-concept without testing them explicitly.

568 If, for some reason, it is not possible to get a reliable index of a poor readers' self-concept -

569 because they are too young, or time and money is limited - a clinician might considering using a

570 child's developmental history to predict if they might be risk of low self-concept or not. If a child

571 has a history of delayed language development or poor attention, the extra time and expense

572 involved in testing academic and general self-concept may be justifiable. However, if a child

573 with poor reading has no history of delayed language or inattention, they may be considered at

574 low risk for any type of low self-concept, and hence no further testing may be required.

575 This latter suggestion highlights a particularly positive finding of this study: Children who

576 have poor reading but no concomitant problems in spoken language or attention do not appear to

577 be at risk for low self-concept. This outcome was not predicted by existing evidence, probably

578 because few previous studies have tested poor readers for their spoken language or attention. Yet

579 again, the exception is Snowling et al. (2007), who reported that their sample of children with

580 poor reading, whose spoken language scores were below the average range as a group, had low

581 academic self-concept but not low social or athletic self-concept. The outcomes of the current

582 study support the finding that poor readers with verbal problems are at risk for low academic

583 self-concept but not social self-concept.

584 Limitations

585 The outcomes of this study, along with its potential theoretical and clinical implications, 
586 must be considered within the context of its methodological strengths and weaknesses. The vast

587 majority of previous studies of self-concept in poor readers tested fewer than 50 poor readers.

588 Thus, the current study joins a relatively rare group of studies with a relatively large sample

589 (Polychroni et al., 2006; Lua \& Chan, 2003; Boetsch et al, 1996, Maughan and Hagell, 1996;

590 Murray, 1978). However, the division of our 77 poor readers into smaller subgroups in the

591 second analysis would reduced the size of individual samples and hence the power of this

592 particular analysis. Effect-size estimates in Table 2 suggest that the lower power of this analysis

593 had minimal impact on the main findings, since all large effects $(\mathrm{N}=6)$ were statistically

594 significant and all small effects $(\mathrm{N}=7)$ were non-significant. It was only a few moderate effects

$595(\mathrm{~N}=3)$ that fluctuated in significance, one being significant in a larger group $(\mathrm{N}=25)$, and two

596 being non-significant in the smaller groups $(\mathrm{N}=13$ and 14). It would be helpful if a future study

597 could clarify the reliability of these few moderate findings using larger groups of poor readers

598 with and without spoken vocabulary and inattention for their different types of low self-concept.

599 Another potential limitation of this study was the use of a single psychometric measure of

600 four different types of self-concept. At this early stage of research, we felt that this was important

601 to ensure that the different scales of self-concept were comparable in terms of norms and

602 reliability and validity. Now we have found that self-concept differs between different types of

603 poor readers, it would be helpful if new, well-powered, studies could use alternative tests of

604 academic self-concept and general self-concept to determine if our findings are replicable with

605 other measures of self-concept.

606 A third limitation of this study is that it was a correlational study rather than a causal study.

607 A correlational approach is useful for starting to develop a theory about which mechanisms

608 might form a causal chain linking poor reading to low self-concept, and for starting to make 
609 predictions in clinical practice about whether a poor reader is at risk for low self-concept, and

610 what type of low self-concept they might have. However, a correlational study cannot tell us the

611 direction of causal effects in a theoretical chain of cognitive factors linking reading and self-

612 concept, and it cannot tell us if clinical practice should treat poor reading to improve self-concept,

613 to treat self-concept to improve poor reading, or to treat both simultaneously. It would therefore

614 be extremely useful if a randomised control trial compared three types of treatment (i.e., reading,

615 self-concept, reading and self-concept) on the academic and general self-concept of poor readers

616 with poor spoken vocabulary and poor readers with inattention.

\section{Summary}

618 The aim of this study was to better understand which types of poor readers have low self-

619 concept. We tested 77 children with poor reading for different types of reading, spoken language,

620 and attention. We discovered that poor readers had disproportionately high number of low scores

621 for their academic and general self-concept but not their home or social self-concept; that poor

622 readers with poor attention had low academic self-concept; that poor readers with poor spoken

623 language and poor attention had low general self-concept as well as low academic self-concept.

624 We also discovered that within poor readers, academic self-concept was reliably associated with

625 reading and spoken vocabulary, while general self-concept was associated primarily with spoken

626 vocabulary. These findings have both theoretical and clinical implications, and encourage further

627 investigations into the heterogeneous nature of self-concept in poor readers.

628 


\section{Acknowledgments}

630 We would like to thank all the children and parents who donated their time and effort to

631 this research; the team of research assistants who helped collecte the data for this project (Kristy

632 Jones, Linda Larsen, Thushara Anandakumar, Huachen Wang, Pip Eve, Kate Glenn); and the

633 reviewers for their valuable contributions to the development of this manuscript. 
634

635

636

637

638

639

640

641

642

643

644

645

646

647

648

649

650

651

652

653

654

655

656

\section{References}

Adams, C., Cooke, R., Crutchley, A., Hesketh, A., \& Reeves, D. (2001). Assessment of Comprehension and Expression. Windsor, UK: NFER Nelson.

Alexander-Passe, N. (2006). How dyslexic teenagers cope: An investigation of self-esteem, coping and depression. Dyslexia, 12, 256-275.

Aro, T., Poikkeus, A. M., Eklund, K., Tolvanen, A., Laakso, M. L., Viholainen, H., ... \& Ahonen, T. (2009). Effects of multidomain risk accumulation on cognitive, academic, and behavioural outcomes. Journal of Clinical Child \& Adolescent Psychology, 38, 883-898. Battle, J. (2002). Culture-Free Self-Esteem Inventories 3rd Edition. Austin, TX: Pro-Ed. Bishop, D. V. M., \& Snowling, M. J. (2004). Developmental dyslexia and specific language impairment: Same or different? Psychological bulletin, 130, 858.

Boetsch, E. A., Green, P. A., \& Pennington, B. F. (1996). Psychosocial correlates of dyslexia across the life span. Development and Psychopathology, 8, 539-562.

Brooks, B. L., Sherman, E. M. S., \& Strauss, E. (2010). NEPSY-II: A Developmental Neuropsychological Assessment, Second Edition. Child Neuropsychology, 16, 80-101. Bull, L. (2007). Sunflower therapy for children with specific learning difficulties (dyslexia): A randomised, controlled trial. Complementary Therapies in Clinical Practice, 13, $15-24$.

Bussing, R., Fernandez, M., Harwood, M., Wei, H., Garvan, C. W., Eyberg, S. M., \& Swanson, J. M. (2008). Parent and teacher SNAP-IV ratings of attention deficit hyperactivity disorder symptoms: Psychometric properties and normative ratings from a school district sample. Assessment, 15, 317-328.

Carroll, J. M., \& Iles, J. E. (2006). An assessment of anxiety levels in dyslexic students in 
657 higher education. British Journal of Educational Psychology, 76, 651-662.

658 Carroll, J. M., Maughan, B., Goodman, R., \& Meltzer, H. (2005). Literacy difficulties and 659 psychiatric disorders: Evidence for comorbidity. Journal of Child Psychology \& Psychiatry, 46, $660 \quad 524-532$.

661 children with mild reading disability. Journal of Developmental and Behavioral Pediatrics, 13, 256-260.

664

Castles, A., Coltheart, M., Larsen, L., Jones, P., Saunders, S., \& McArthur, G. (2009).

665

Assessing the basic components of reading: A revision of the Castles and Coltheart test with new 666 norms. Australian Journal of Learning Difficulties, 14, 67-88.

667

Catts, H. W., Adlof, S. M., Hogan, T. P., \& Weismer, S. E. (2005). Are specific language 668 impairment and dyslexia distinct disorders? Journal of Speech, Language, and Hearing Research, 48, 1378-1396.

670

Cohen, J. (1992). A power primer. Psychological Bulletin, 112, 155-159.

671

Cole, D. A., Maxwell, S. E., Martin, J. M., Peeke, L. G., Seroczynski, A. D., Tram, J. M., 672 ... \& Maschman, T. (2001). The development of multiple domains of child and adolescent self-concept: A cohort sequential longitudinal design. Child Development, 72, 1723-1746. risk factors predicting readiness for learning in children at high risk of dyslexia. Development and Psychopathology, 1-10. 
Bloomington, MN: NCS Pearson. disability: Separate but often overlapping disorders. Journal of Learning Disabilities, 24, 96-103. impairment: The role of phonology and auditory processing. Scientific Studies of Reading, 14, 8688 29. performance and the perceived scholastic competence, global self-worth and achievement of children with dyslexia. School Psychology International, 22, 401-416. comorbidity: attention-deficit hyperactivity disorder and dyslexia. Journal of the American 694 Academy of Child \& Adolescent Psychiatry, 31, 343-348.

695 Gresham, F. M., \& Vellutino, F. R. (2010). What is the role of intelligence in the 696 identification of specific learning disabilities? Issues and clarifications. Learning Disabilities 697 Research \& Practice, 25, 194-206.

698 Harter, S. (1990). Processes underlying adolescent self-concept formation. In R. 699 Montemayor, G. Adams, \& T. Gullotta (Eds.), From childhood to adolescence: A transitional 700 period? (pp. 205-239). Thousand Oaks, CA: Sage 

specific and global self-evaluations of learning-disabled, behaviorally disordered, and normally achieving adolescents. American Educational Research Journal, 35, 653-680.

Herbers, J. E., Cutuli, J. J., Supkoff, L. M., Heistad, D., Chan, C.-K., Hinz, E., \& Masten, 705

A. S. (2012). Early reading skills and academic achievement trajectories of students facing poverty, homelessness, and high residential mobility. Educational Researcher, 41, 366-374. dyslexia. Journal of Research in Special Educational Needs, 2.

Kaufman, A., \& Kaufman, N. (2004). Kaufman Brief Intelligence Test 2. Circle Pines, MN: AGS.

Korkman, M., Kirk, U., \& Kemp, S. (1998). NEPSY: A developmental neuropsychological assessment. San Antonio, USA: Psychological Corporation. speech and language difficulties. British Journal of Educational Psychology, 70, 583-601. good and poor readers in Hong Kong. Journal of Research in Reading, 26, 177-190. perspectives. Perspectives on Psychological Science, 1, 133-163.

Marsh, H. W., \& Martin, A. J. (2011). Academic self-concept and academic achievement:

721 Relations and causal ordering. British Journal of Educational Psychology, 81, 59-77 
structure. Educational Psychologist, 20, 107-123.

726

Martínez, R. S., \& Semrud-Clikeman, M. (2004). Emotional adjustment and school

727 functioning of young adolescents with multiple versus single learning disabilities. Journal of

728 Learning Disabilities, 37, 411-420.

729 Maughan, B., \& Carroll, J. (2006). Literacy and mental disorders. Current Opinion in

730 Psychiatry, 19, 350-354.

731 Maughan, B., \& Hagell, A. (1996). Poor readers in adulthood: Psychosocial functioning.

732 Development and Psychopathology, 8, 457-476.

733 McArthur, G., \& Castles, A. (2013). Phonological processing deficits in specific reading

734 disability and specific language impairment: same or different? Journal of Research in Reading,

$73536,280-302$.

736 McArthur, G. M., \& Hogben, J. H. (2001). Auditory backward recognition masking in

737 children with a specific language impairment and children with a specific reading disability. The

738 Journal of the Acoustical Society of America, 109, 1092-1100.

739 McArthur, G. M., Hogben, J. H., Edwards, V. T., Heath, S. M., \& Mengler, E. D. (2000).

740 On the "specifics" of specific reading disability and specific language impairment. Journal of

741 Child Psychology \& Psychiatry \& Allied Disciplines, 41, 869.

742 McArthur, G. M., Jones, K., Anandakumar, T., Larsen, L., Castles, A., \& Coltheart, M.

743 (2013). A Test of Everyday Reading Comprehension. Australian Journal of Learning

744 Difficulties, 18, 35-85.

745 McArthur, G.M., Kohnen, S., Larsen, L., Jones, K., Anandakumar, T., Banales, E., \&

746 Castles, A. (2013). Getting to grips with the heterogeneity of developmental dyslexia. Cognitive 
747 Neuropsychology, 30, 1-24.

748 Moore, D., Porter, M.A., Kohnen, S., \& Castles, A. (2012). Detecting different types of

749 reading difficulties: A comparison of tests. Australasian Journal of Special Education, 36, 112750133.

751 Morgan, P. L., Fuchs, D., Compton, D. L., Cordray, D. S., \& Fuchs, L. S. (2008). Does

752 early reading failure decrease children's reading motivation? Journal of Learning Disabilities, $753 \quad 41,387-404$.

754 Murray, M. E. (1978). The relationship between personality adjustment and success in 755 remedial programs in dyslexic children. Contemporary Educational Psychology, 3, 330-339. 756 Neale, M. (1999). Neale analysis of reading ability (3rd ed.). Melbourne: Australian 757 Council for Educational Research.

758 Organisation for Economic Cooperation and Development (2003). Student engagement at 759 school: A sense of belonging and participation. Paris: OECD.

760 Polychroni, F., Koukoura, K., \& Anagnostou, I. (2006). Academic self-concept, reading 761 attitudes and approaches to learning of children with dyslexia: Do they differ from their peers? 762 European Journal of Special Needs Education, 2, 415-430.

763 Riddick, B. (2009). Living with dyslexia: The social and emotional consequences of 764 specific learning difficulties/disabilities. London, UK: Routledge.

765 Rispens, J., \& Been, P. (2007). Subject-verb agreement and phonological processing in 766 developmental dyslexia and specific language impairment (SLI): A closer look. International 767 Journal of Language \& Communication Disorders, 42, 293-305.

768 Semrud-Clikeman, M., Biederman, J., Sprich-Buckminster, S., Lehman, B. K., Faraone, S. 769 V., \& Norman, D. (1992). Comorbidity between ADDH and learning disability: A review and 
770 report in a clinically referred sample. Journal of the American Academy of Child \& Adolescent

771 Psychiatry, 31, 439-448.

772 Shaywitz, S. E., Escobar, M. D., Shaywitz, B. A., Fletcher, J. M., \& Makuch, R. (1992).

773 Evidence that dyslexia may represent the lower tail of a normal distribution of reading ability.

774 New England Journal of Medicine, 326, 145-150.

775 Shaywitz, B. A., Fletcher, J. M., \& Shaywitz, S. E. (1995). Defining and classifying

776 learning disabilities and attention-deficit/hyperactivity disorder. Journal of Child Neurology.

777 Shirk, S. R. (1988). What is child psychotherapy? In S. R. Shirk (Ed.), Cognitive

778 development and child psychotherapy (pp. 1-16). New York: Plenum Press.

779 Siegel, L. S. (1989). IQ is irrelevant to the definition of learning disabilities. Journal of

780 Learning Disabilities, 22, 469-478.

781 Smart, D., Prior, M., Sanson, A., \& Oberklaid, F. (2001). Children with reading

782 difficulties: A six year follow-up from early primary school to secondary school. Australian

783 Journal of Psychology, 53, 45-53.

784 Snowling, M. J., Muter, V., \& Carroll, J. (2007). Children at family risk of dyslexia: A

785 follow-up in early adolescence. Journal of Child Psychology \& Psychiatry, 48, 609-618.

786 Stuart, M., \& Stainthorpe, R., (2016). Reading development and teaching. London, UK:

787 Sage.

788 Swanson, J. M., Sandman, C. A., Deutsch, C., \& Baren, M. (1983). Methylphenidate

789 hydrochloride given with or before breakfast: I. Behavioral, cognitive, and electrophysiologic

790 effects. Pediatrics, 72, 49.

791 Taylor, L. M., Hume, I. R., \& Welsh, N. (2010). Labelling and self-esteem: The impact of

792 using specific vs. generic labels. Educational Psychology, 30, 191-202. 
794 functioning: An exploratory study of the role of self-esteem and understanding. Dyslexia, 15, $795 \quad 304-327$

796 Thomson, M. E., \& Hartley, G. M. (1980). Self-concept in dyslexic children. Intervention 797 in School and Clinic, 16, 19-36.

798 Torgesen, J. K., Wagner, R. K., \& Rashotte, C. A. (1999). Test of Word Reading 799 Efficiency. Austin, TX: Pro-Ed.

800 Treuting, J. J., \& Hinshaw, S. P. (2001). Depression and self-esteem in boys with attention801 deficit/hyperactivity disorder: Associations with comorbid aggression and explanatory 802 attributional mechanisms. Journal of Abnormal Child Psychology, 29, 23-39.

803 Westervelt, V. D., Johnson, D. C., Westervelt, M. D., \& Murrill, S. (1998). Changes in 804 self-concept and academic skills during a multimodal summer camp program. Annals of 805 Dyslexia, 48, 191-212.

806 Wheldall, K., \& McMurtry, S. (2014). Preliminary evidence for the validity of the new 807 Test of Everyday Reading Comprehension. Australian Journal of Learning Difficulties, 19, 173808178.

Willcutt, E. G., \& Pennington, B. F. (2000). Comorbidity of reading disability and 810 attention-deficit/hyperactivity disorder differences by gender and subtype. Journal of learning 811 disabilities, 33, 179-191.

812 Willcutt, E. G., Pennington, B. F., Boada, R., Ogline, J. S., Tunick, R. A., Chhabildas, N. 813 A., \& Olson, R. K. (2001). A comparison of the cognitive deficits in reading disability and 814 attention-deficit/hyperactivity disorder. Journal of abnormal psychology, 110, 157.

815 Zeleke, S. (2004). Self-concepts of students with learning disabilities and their normally 
816 achieving peers: A review. European Journal of Special Needs Education, 19, 145-170.

817 


\section{Table $\mathbf{1}$ (on next page)}

Sample characteristics

Mean (M), Standard Deviation (SD), Minimum (Min) and Maximum (Max) Standard Scores (StS; $M=100, S D=15)$, Scaled Scores $(S c S ; M=10, S D=3)$ and $Z$ Scores $(z ; M=0, S D=$ 1) Produced by our Sample of Poor Readers $(N=77)$. 


\section{Table 1}

Mean (M), Standard Deviation (SD), Minimum (Min) and Maximum (Max) Standard Scores $(S t S ; M=100, S D=15)$, Scaled Scores $(S c S ; M=10, S D=3)$ and $Z$ Scores $(z ; M=0, S D=$ 1) Produced by our Sample of Poor Readers $(N=77)$.

\begin{tabular}{|c|c|c|c|c|}
\hline & $M$ & $S D$ & Min & $\operatorname{Max}$ \\
\hline Age (years) & 10.46 & 1.01 & 9.00 & 12.50 \\
\hline Sex $(1=$ female; 2 = male $)$ & 1.42 & 0.50 & 1 & 2 \\
\hline Nonverbal IQ (StS) & 98.52 & 15.77 & 64 & 138 \\
\hline \multicolumn{5}{|c|}{ Reading } \\
\hline Phonological recoding (z) & -1.73 & 0.66 & -3.09 & 0.66 \\
\hline Visual word recognition $(\mathrm{z})$ & -1.36 & 0.74 & -3.09 & 0.94 \\
\hline Reading fluency (z) & -1.00 & 0.82 & -3.07 & 0.67 \\
\hline Reading comprehension (z) & -0.86 & 1.01 & -3.09 & 1.22 \\
\hline \multicolumn{5}{|c|}{ Self-concept } \\
\hline Academic (ScS) & 8.53 & 2.84 & 1 & 13 \\
\hline General (ScS) & 8.23 & 2.98 & 2 & 14 \\
\hline Home (ScS) & 10.31 & 2.62 & 2 & 13 \\
\hline Social (ScS) & 9.62 & 3.06 & 1 & 13 \\
\hline
\end{tabular}

\section{Spoken language}

$\begin{array}{lllll}\text { Phonological processing (ScS) } & 9.14 & 2.19 & 1 & 13 \\ \text { Receptive vocabulary (StS) } & 97.52 & 11.69 & 73 & 130 \\ \text { Expressive vocabulary (ScS) } & 7.73 & 2.22 & 3 & 16\end{array}$

\section{Attention}

$\begin{array}{llllll}\text { Inattention }(/ 3) & & 1.28 & .68 & .11 & 2.78\end{array}$


Inattention (z)

Hyperactivity (/3)

Hyperactivity (z)
.56

.59

$-0.07$
.82

.56

.93
$-.98$

2.15

2.65

1 


\section{Table 2 (on next page)}

Poor readers' self-concept scores

Means (M), Standard Deviations (SD), Medians (Md), Wilcoxon Signed Rank Test Values (Z), $P$

Values (p), and Effect Size Values (r) For Self-Concept Scores Produced By Our Sample Of Poor Readers $(N=77) . r=0.1,0.3$, and 0.5 Represent Small, Medium, And Large Effects Respectively. 


\section{Table 2}

Means (M), Standard Deviations (SD), Medians (Md), Wilcoxon Signed Rank Test Values (Z), $P$ Values (p), and Effect Size Values (r) For Self-Concept Scores Produced By Our Sample Of Poor Readers $(N=77) . r=0.1,0.3$, and 0.5 Represent Small, Medium, And Large Effects Respectively.

\begin{tabular}{|c|c|c|c|c|c|}
\hline \multirow[t]{2}{*}{ Group } & \multirow[t]{2}{*}{ Statistics } & \multicolumn{4}{|c|}{ Self-concept } \\
\hline & & Academic & General & Home & Social \\
\hline \multirow{6}{*}{$\begin{array}{l}\text { Reading } \\
\mathrm{N}=25\end{array}$} & $\mathrm{M}$ & 9.32 & 9.76 & 11.16 & 10.64 \\
\hline & SD & 2.27 & 2.57 & 3.00 & 3.05 \\
\hline & $\mathrm{Md}$ & 9.00 & 10.00 & 11.00 & 12.00 \\
\hline & Z & -1.11 & -0.39 & 2.82 & 1.68 \\
\hline & $\mathrm{p}$ & .14 & .34 & .002 & .04 \\
\hline & $\mathrm{r}$ & .22 & .08 & .56 & .34 \\
\hline \multirow{6}{*}{$\begin{array}{l}\text { Reading + Language } \\
\mathrm{N}=24\end{array}$} & $\mathrm{M}$ & 7.63 & 6.88 & 9.58 & 8.83 \\
\hline & SD & 3.56 & 2.38 & 3.22 & 3.45 \\
\hline & $\mathrm{Md}$ & 9.00 & 7.00 & 10.00 & 10.00 \\
\hline & $\mathrm{Z}$ & -2.69 & -3.93 & -0.13 & -1.27 \\
\hline & $\mathrm{p}$ & .004 & $<.001$ & .44 & .10 \\
\hline & $\mathrm{r}$ & .55 & 0.80 & 0.03 & 0.26 \\
\hline \multirow{6}{*}{$\begin{array}{l}\text { Reading }+ \text { Attention } \\
\mathrm{N}=14\end{array}$} & $\mathrm{M}$ & 8.57 & 8.64 & 10.14 & 10.14 \\
\hline & $\mathrm{SD}$ & 2.71 & 3.43 & 2.77 & 2.63 \\
\hline & $\mathrm{Md}$ & 9.00 & 9.50 & 11.00 & 10.50 \\
\hline & $\mathrm{Z}$ & -1.75 & -1.30 & .40 & -.18 \\
\hline & $\mathrm{p}$ & .04 & .10 & .34 & .43 \\
\hline & $\mathrm{r}$ & .47 & .35 & .11 & .05 \\
\hline
\end{tabular}




\begin{tabular}{lccccc}
\hline $\begin{array}{l}\text { Reading + Language }+ \\
\text { Attention } \\
\mathrm{N}=13\end{array}$ & $\mathrm{M}$ & 8.69 & 7.69 & 10.23 & 8.92 \\
& $\mathrm{SD}$ & 2.32 & 2.98 & 2.01 & 2.10 \\
& $\mathrm{Md}$ & 9.00 & 7.00 & 10.00 & 9.00 \\
& $\mathrm{Z}$ & -1.83 & -2.61 & 0.41 & -1.62 \\
& $\mathrm{p}$ & .04 & .004 & .34 & .05 \\
& $\mathrm{r}$ & .51 & .72 & .11 & .45
\end{tabular}

1 


\section{Table 3 (on next page)}

Relationships between academic and general self-concept and reading, language, and attention.

Spearman Rho Rank Correlation Coefficients Between Academic and General Self-concept and (1) Reading Ability (Phonological Recoding Accuracy, Visual Word Recognition Accuracy, Reading Fluency, and Reading Comprehension Separately), (2) Spoken Language Ability (Phonological Processing and Spoken Vocabulary Knowledge), and (3) Attention (Inattention and Hyperactivity). Statistically Significant Coefficients are Marked in Grey (two-tailed; $p<$ $.05)$. 


\section{Table 3}

Spearman Rho Rank Correlation Coefficients Between Academic and General Self-concept and (1) Reading Ability (Phonological Recoding Accuracy, Visual Word Recognition Accuracy, Reading Fluency, and Reading Comprehension Separately), (2) Spoken Language Ability (Phonological Processing and Spoken Vocabulary Knowledge), and (3) Attention (Inattention and Hyperactivity). Statistically Significant Coefficients are Marked in Grey (two-tailed; $p<.05$ ).

\begin{tabular}{lllll}
\hline & \multicolumn{2}{c}{ Academic self-concept } & \multicolumn{2}{l}{ General self-concept } \\
& $\boldsymbol{r}_{\boldsymbol{s}}$ & $\boldsymbol{p}$ & $\boldsymbol{r}_{\boldsymbol{s}}$ & $\boldsymbol{p}$ \\
\cline { 2 - 5 } Phonological recoding & .24 & .04 & .01 & .94 \\
Visual word recognition & .33 & .004 & .20 & .09 \\
Reading fluency & .42 & $<.001$ & .22 & .05 \\
Reading comprehension & .29 & .01 & .29 & .01 \\
Phonological processing & .13 & .25 & .16 & .18 \\
Receptive Vocabulary & .28 & .01 & .40 & $<.001$ \\
Expressive Vocabulary & .10 & .37 & .26 & .02 \\
Inattention & -.22 & .06 & -.16 & .17 \\
Hyperactivity & .11 & .33 & -.06 & .63 \\
\hline
\end{tabular}




\section{Figure 1}

Figure 1. Median reading scores (with upper and lower quartiles) of the four groups.

The horizontal line represents the median level expected for each child's age (i.e., a z score of 0 ). Any median (short black horizontal line) that falls within a patterned box that falls below the horizontal line suggests a statistically reliable low median score for that type of self-concept for that group.

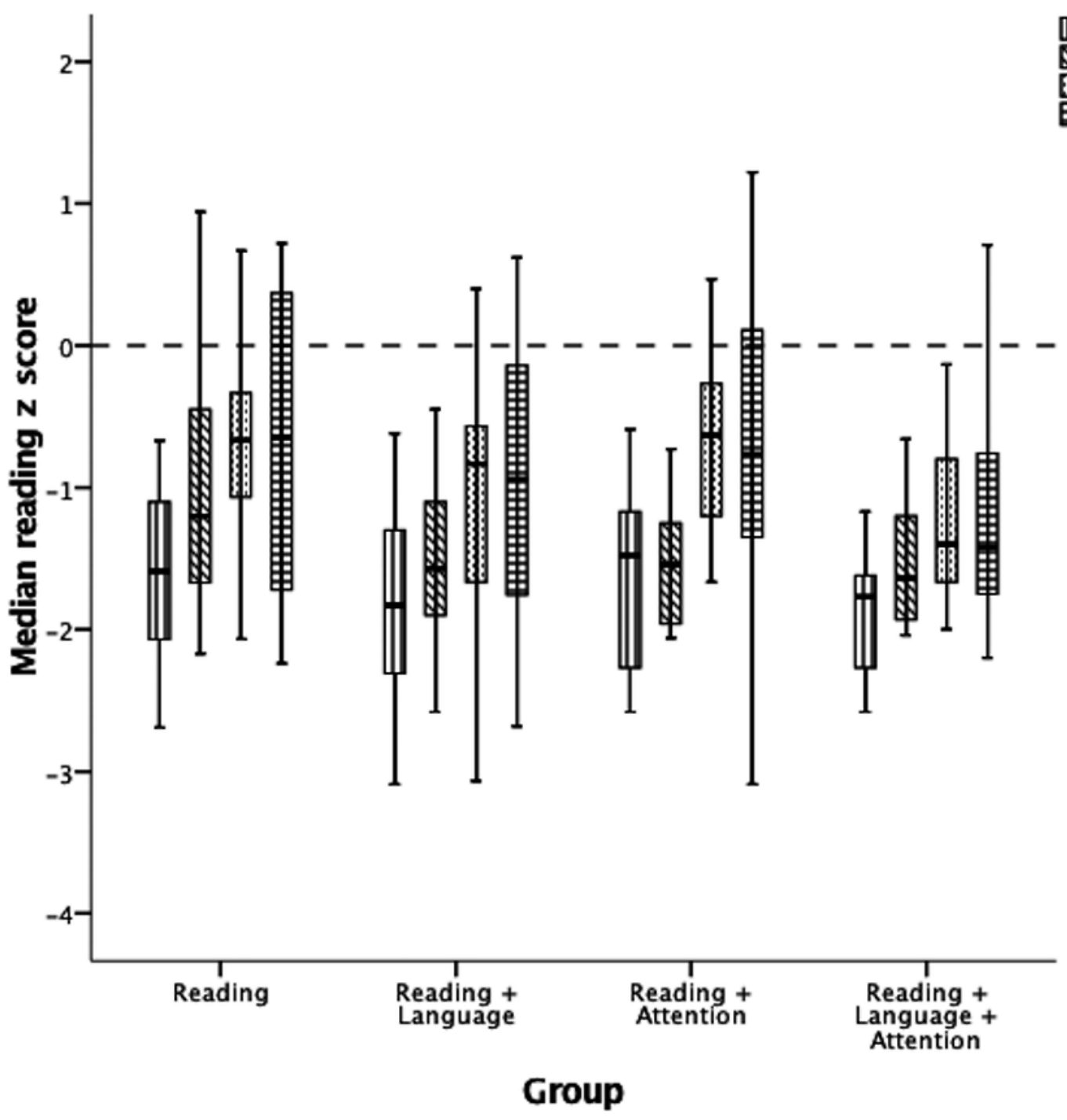


Figure 2

Figure 2. Median self-concept scores (with upper and lower quartiles) of the four groups.

The horizontal line represents the median level expected for each child's age (i.e., a scaled score of 10). Any median within a patterned box that falls below the horizontal line suggests a distribution of scores that might be statistically significantly different to the mean level expected for age.

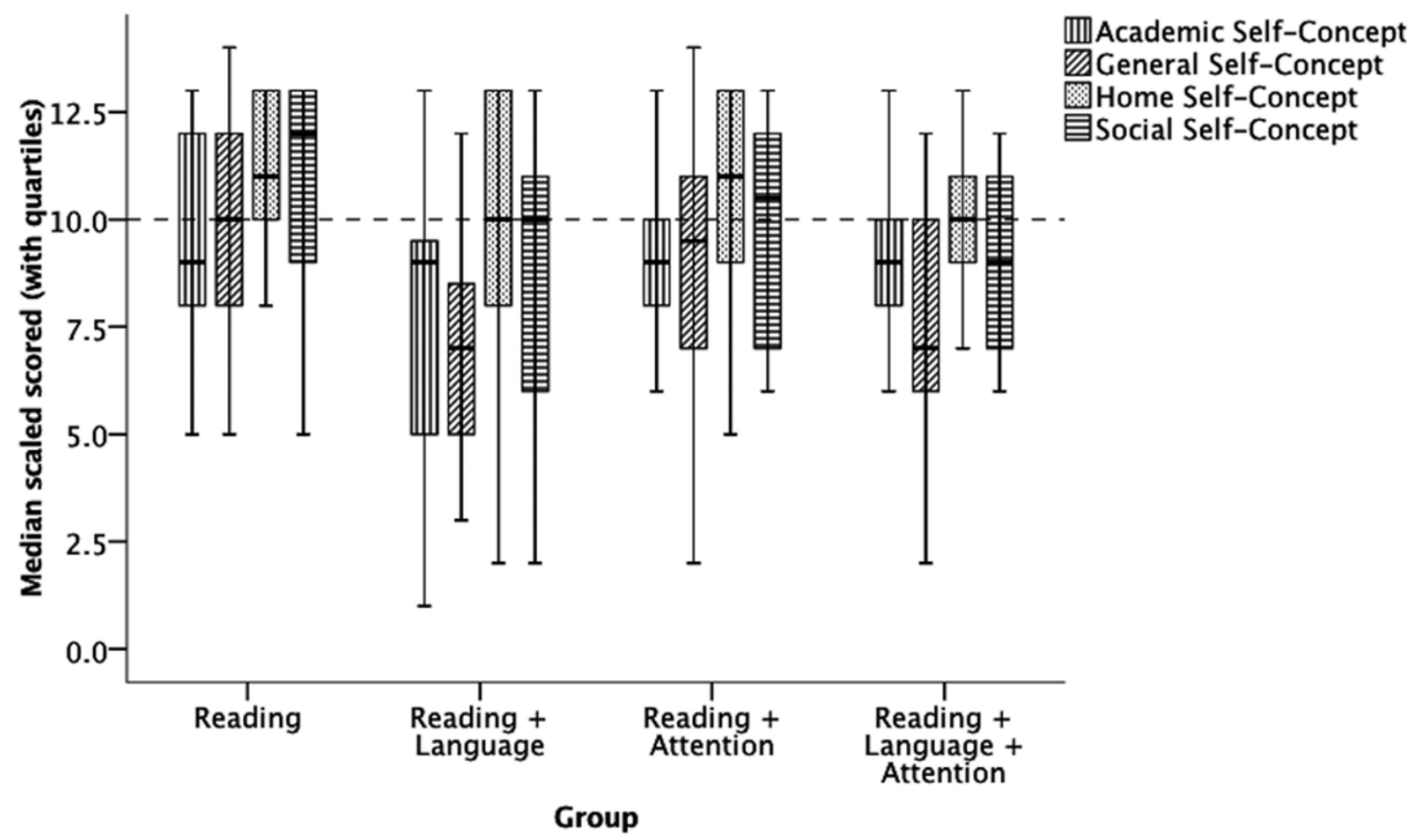




\section{Table 4 (on next page)}

Relationships between home and social self-concept and reading, language, and attention.

Spearman Rho Rank Correlation Coefficients Between Home and Social Self-concept and Reading Ability (Phonological Recoding Accuracy, Visual Word Recognition Accuracy, Reading Fluency, and Reading Comprehension Separately), Spoken Language Ability (Phonological Processing and Spoken Vocabulary Knowledge), and Attention (Inattention and Hyperactivity). Statistically Significant Coefficients are Marked in Grey (two-tailed; $p<.05$ ). 
1

2

Spearman Rho Rank Correlation Coefficients Between Home and Social Self-concept and Reading Ability (Phonological Recoding Accuracy, Visual Word Recognition Accuracy, Reading Fluency, and Reading Comprehension Separately), Spoken Language Ability (Phonological Processing and Spoken Vocabulary Knowledge), and Attention (Inattention and Hyperactivity). Statistically Significant Coefficients are Marked in Grey (two-tailed; $p<.05$ ).

\section{Home self-concept Social self-concept}

Phonological recoding $\boldsymbol{r}_{\boldsymbol{s}}$

$p$

$\boldsymbol{r}_{s}$

p

.06

.08

.47

.05

.19

.25

Reading comprehension

.19

.03

.09

.10

.39

.30

.008

.30

.24

.09

.18

$-.17$

.15

Inattention

$-.19$

.11

.79

$-.02$

$-.17$

.14 